\author{
Monica ȚICHINDELEAN (BECA), PhD Candidate \\ E-mail: monibeca@gmail.com \\ Professor Iuliana CETINĂ, PhD \\ E-mail: cetina.iuliana@gmail.com \\ Faculty of Marketing \\ The Bucharest University of Economic Studies \\ Lecturer Mihai T,ICHINDELEAN, PhD \\ E-mail: mihai.tichindelean@ulbsibiu.ro \\ Faculty of Economic Sciences \\ Lucian Blaga University of Sibiu \\ Professor Violeta RĂDULESCU, PhD \\ E-mail: Violeta.radulescu@mk.ase.ro \\ Faculty of Marketing \\ The Bucharest University of Economic Studies
}

\title{
USABILITY OF BANKING WEBSITES - AN EYE-TRACKER STUDY
}

Abstract. The present article aims to study users' experience on banking websites by eye tracking the gaze of 22 subjects while performing a task on the homepage of five banking websites. After data form the eye tracker was correlated with perceptions regarding the ease of performing the task on each website, several conclusions regarding the influence of the website structure over users' experience could be made. First of all, the gaze of the users while surfing the banking webpages seems to follow a vertical direction, with accent on information highlighted by different colors, fonts or by the use of images; the upper part of the website is the first and most viewed one, followed by the right side of the screen. As the difficulty of performing the task on the website was both measured (duration needed for completing the task) and expressed by the subjects, the results of the performed ANOVA showed that both dimensions vary according to the structure of the webpages. The value of the correlation coefficients calculated for the two variables indicate that the subjects correctly evaluated the difficulty of the task, the relationship between them being a negative one.

Keywords: attention, eye tracking, online banking, website design.

JEL Classification : M31, M37, D87, D12

\section{Introduction}

Understanding consumer behavior dimensions such as attention, perception or preferences is a desideratum for any marketing specialist. Traditional marketing

DOI: $10.24818 / 18423264 / 53.4 .19 .08$ 
Monica Țichindelean (Beca), Iuliana Cetină, Mihai Țichindelean, Violeta Rădulescu

research techniques such as interview or survey can generate valuable information regarding consumers' behavior, still this information has limited validity as it is filtered by consumers' subjectivity before being expressed. This limit of traditional research can be overcome by combining it with neuromarketing research, thus offering the possibility for expressed information to be correlated with data directly obtained from the brain's or body's reactions to marketing stimuli.

Many of the actual businesses tend to grow their presence in the online environment, thus understanding what makes a website appealing becomes vital in keeping a business successful. One of the frequent techniques used in website usability studies is eye tracking; this allows for information about the gaze and attention of the users to be studied while they surf a webpage, thus understanding which type of information is more appealing.

In the first part, this article aims at discussing the eye tracking technique contributions in the field of marketing by analyzing past research results, while the second part of the paper presents an example of eye tracking research in the field on banking industry, namely the identification of website structure importance in banking websites usability. Based on the four objectives derived from the purpose of the research, relevant and useful results are presented that can contribute to improving users' experience when referring to banking websites.

\section{Literature review}

\section{Measuring attention through the eye tracker technique}

One of the most important marketing research areas is consumer behavior (Cătoiu, 2009) which is, without any doubt, a mix of human feelings, principles, traditions, social and normative elements (Smeureanu, 2014). In today's age of product abundance, mass and one-to-one communication, and more and more educated consumers, the battle for their attention is on-going and demanding new insight. Recording, measuring and understanding attention drivers is not an easy thing to achieve. Traditional research methods such as survey or interview can provide information regarding the attention focus of consumers while interacting with a marketing stimulus, by analyzing the memorized information and its resource (Mohr et al., 2012); still, within a survey or an interview, memorized information is presented by the respondents after being filtered by their own perceptual system, therefore information risking to be altered or incomplete. Within the relatively new research field of neuromarketing - research method that focuses on increasing the effectiveness of marketing activities by studying brain responses (Smidts, 2002) - the eye tracking or the study of pupil dilation techniques provide valuable information regarding what consumers see and how their cognitive process is influenced by the information received. While recording pupil dilation (or contraction) allows further understanding of how the content of a 
stimulus impacts the consumer's emotions (Hoeks and Levelt, 1993, Pop et. al., 2014), the eye tracking technique allows researchers to identify the attention attracting elements of a marketing stimulus by recording the position, duration and scan path of the consumer's gaze during his/her interaction with the stimulus, afterward being able to associate this information with the cognitive and emotional responses of the consumer (Pieters et al., 1999; Fidelis et al., 2017). As nowadays the eye tracking technique is widely used in the field of marketing as part of neuromarketing research method, the beginning of eye tracking studies can be established around 1870 when subjects' gaze was recorded and studied for the first time with the purpose of establishing the linearity of the reading process, different medical usages of this technology being present in the literature (Płużyczka, 2018).

When referring to the use of eye tracking technique in the field of neuromarketing, if we think about the AIDA model (attention, interest, desire and action), the data obtained from the eye tracker is able to answer a wide set of questions regarding the first two dimensions: attention and interest of consumers related to marketed products and services (Bojko, 2013).

As different marketing aspects such as product packaging effectiveness (Milosavljevic et al., 2011), ideal shelf positioning (Durgin, et al., 2008) or online and offline advertising impact (Pieters and Wedel, 2007; Munoz-Leiva et al., 2019) have been studied trough the eye tracker along the time, a special focus can be identified in the study of website usability. In order to test the efficiency of highlighted text versus non-highlighted text in attention grabbing, Chi et al. (2007) applied 12 questions to a group of 6 subjects and studied how their attention was directed by different types of text. The results clearly indicated that users are more likely to search for answers in highlighted sections of the text rather than the ones which are not highlighted, confirming the von Restorff isolation effect which presumes that a higher interaction and memory rate will be obtained for the areas isolated from a homogeneous background. Cyra at el. (2010) present an interesting approach over website design, namely the impact of color on satisfaction, user trust and e-loyalty and the impacted differences across three different users' culture. By using the eye tracking technique, the authors recorded the gaze of the 90 subjects (from Japan, Canada and Germany) while surfing an e-commerce website. Designed as a two-factorial experiment (website color and respondent's culture), the eye tracking results were afterwards completed by subjects' expressed perceptions obtained by using survey and interview as methods. Results of the study show that website color significantly influences trust and satisfaction over an e-commerce website, while color preference was influenced by nationality: German subjects preferred the yellow design, Canadians the grey one and Japanese preferred the blue theme of the e-commerce website. Another approach of website usability is made by Djamasbi et al. (2010), this time the studied variable being the specificity of generation Y online visual attention. Based on the results of a survey regarding the visual appeal of 50 webpages applied on 98 generation Y participants, 3 most liked and 3 least liked webpages were chosen for the eye

DOI: $10.24818 / 18423264 / 53.4 .19 .08$ 
Monica Țichindelean (Beca), Iuliana Cetină, Mihai Țichindelean, Violeta Rădulescu

tracking study. As visual fixation of participants was recorded through the experiment, further information about visual appealing rate of each page was obtained through survey and interviews with the participants. The results showed that the elements that might increase the attractiveness of a webpage for generation $\mathrm{Y}$ users are the large images, the use of celebrity images, the lack of text and the existence of a search feature. In the same field of age-related web design efficiency, Bergstrom et al. (2013) study the difference of attention and perception of different age groups over different website designs. A total number of 37 subjects were assigned to participate in one of the five eye tracking experiments, where different parts of the webpage where defined as areas of interest (AOI). By studying the fixations and the elapsed time until the first fixation, the following interesting results regarding older users' attention have been obtained: older users tend to focus their attention in the center of the webpage and less on the peripheral areas, compared to younger users who act in an opposite way; regarding the duration until first fixation, significant differences were found regarding the top peripheral area, namely older users fixate on this area much later than young ones. Switching from the effect of age to the effect of cognitive load over visual attention while surfing a website, Wang et al. (2014) study the attention of 42 students performing simple and complex tasks on simple and complex structure online shopping websites. After performing statistical tests on the data obtained from the eye tracker (ANOVA), the authors were able to conclude that task complexity influences usability in a larger amount compared to website complexity: performing a simple task on a complex website showed no statistical difference of fixation duration compared to simple web design, while performing a complex task in a medium-complex website resulted in the highest duration for completing the task, highest fixation number and highest fixation duration. In terms of website structure and complexity, in one of the most recent studies, Zlokazova et al. (2019) compare the two most common ways to present two-way flight offers on airlines or travel agency websites: all information on one page or each route on a separate, consecutive page. By using the eye tracker and mouse tracker, Zlokazova and her colleagues analyzed the performance speed and error rate of 23 users interacting with each of the two design options. The results showed that the two-page design allows for the lowest performance duration but resulted in a higher number of errors during the process as a result of higher cognitive load. In their study, Menon et all (2016) have researched the consumer's attention for price in an online commerce environment (social media network page) by varying the price points, price position, and the existence of a mannequin or a known model. In this setting, the consumer's attention was associated (and measured by using the eye-tracker) with the fixation time on price, respectively on the overall social network page. Their results indicated a U-shaped curve having price values on the abscise, and fixation time on the ordinate. Thus, price and gender-specific salient (known model

DOI: 10.24818/18423264/53.4.19.08 
for men for fixation time of the whole social network page) captures the consumer's attention in the cluttered apparel online environment.

\section{Methodology}

Preliminary research phase: Past research performed by the authors concluded that the website is one of the most efficient communication means used by banking institutions as part of their marketing communication strategy. As banking marketers seem to be most interested in decoding and understanding the behavior of consumers while surfing their banking website, the present paper aims to study the duration (measured difficulty) and perception (perceived difficulty) of consumers over fulfilling a task on the homepage of banking websites. The final purpose of the research is to identify the structure of a banking website landing page that increases its ease of use. Derived from the purpose of the research, the following objectives and hypothesis were established:

- Objective 1 - Determining the order in which subjects visualize the elements on each of the five banking websites, while searching for the exchange rate;

o Hypothesis H1: a pattern of visualization can be established

- Objective 2-Determining the differences (ANOVA) of the perceived difficulty for identifying the exchange rate between the banks' websites; o Hypothesis H2: the perceived difficulty as a result of carrying out the task differs significantly depending on the website of the considered banks

- Objective 3-Determining the differences (ANOVA) of the measured difficulty (duration) in completing the task between the banks' websites; o Hypothesis 3: the measured difficulty (the duration) following the fulfillment of the task differs significantly depending on the website of the considered banks

- Objective 4 - Identifying the relationship between the perceived and measured difficulty for completing the task

o Hypothesis 4: the relationship between the perceived difficulty of carrying out the task and the measured difficulty is a direct, negative one.

Projection research phase: Using survey (questionnaire) and neuromarketing (eye tracking) research methods, the analyzed data was collected from a randomly created, non-representative sample of 22 subjects (11 females, 11 men), between 25.03.2019 -01.04.2019.

After carefully reviewing the information provided by the researchers, each subject signed a consent form for participating in the study. Following the completion of an initial questionnaire, the subjects were set in front of a laptop that had the eye tracker mounted on. Before starting the experiment, the eye tracker was calibrated for each subject, therefore assuring an accurate recording of their gaze. The home pages of five banking websites were chosen as visual stimuli for the experiment; four tasks were given subsequently to the subjects for each of the 
Monica Țichindelean (Beca), Iuliana Cetină, Mihai Țichindelean, Violeta Rădulescu

five websites: (1) to identify the bank's exchange rate, (2) to identify the shopping card information section, (3) to identify the mobile banking application section and (4) 1 minute free viewing of the landing webpage. During each of the tasks, the eye tracker recorded the subjects' eyes, as well as the duration forcompleting each task. Following the completion of tasks 1,2 and 3, the subjects assessed the difficulty for completing the task; after the $4^{\text {th }}$ task, each subject completed a second, more detailed questionnaire.

The data obtained using the eye tracker and by applying the questionnaire were encoded and processed using the IBM SPSS statistical analysis program, version 22. The present paper presents the results regarding the measured and perceived difficulty of completing task 1 (identifying the exchange rate offered by each of the five banks on their website) after exclusion of outliers (data for which their standardized value was outside the $[-2,2]$ interval).

\section{Empirical findings}

Objective 1 - Determining the order in which subjects visualize the elements on each of the five banking websites, while searching for the exchange rate

In the process of identifying the exchange rate offered by the five considered banks on their websites, each subject focused his/her attention on different elements and information from the web page. By using the data provided by the Areas of Interest (AOI) map generated by the eye tracker (viewing sequence, duration etc.), a scan pathmap of the first 10 elements that attracted the visual attention of the users was developed. The following figure presents an example of scan path map of the first 10 elements viewed on Piraeus Bank website.

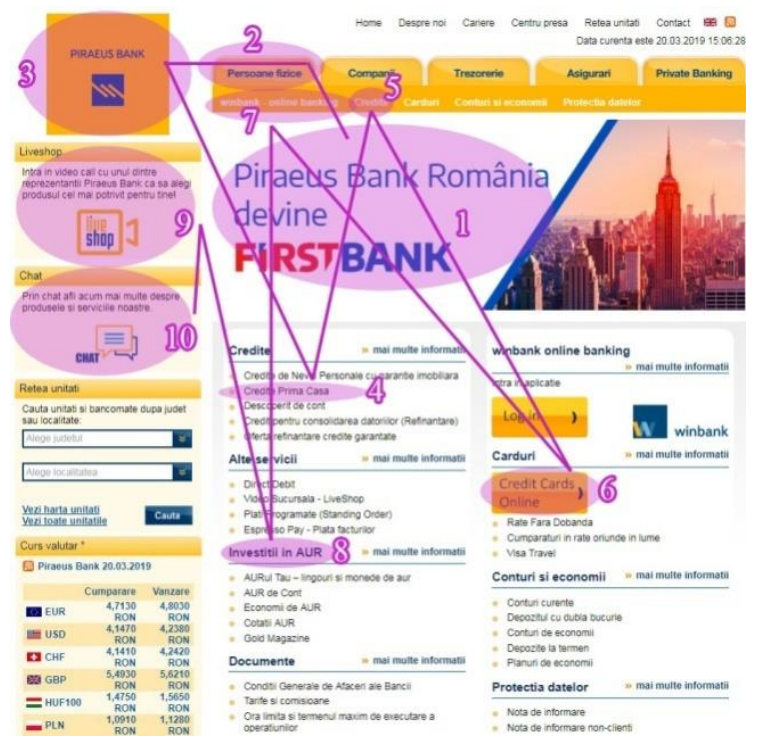


Figure 1. Scan path map of the first 10 viewed elements on Piraeus Bank website

By analyzing each of the five scan path maps, a series of conclusions regarding the visualization order and attention attractor elements can be drawn:

- At a general level we cannot identify a visualization order, the gaze following a chaotic path, guided by the main sections and the way they are highlighted by colors, buttons or images; in terms of direction, the gaze tends to follow an initial vertical route, followed by a shift of attention towards the attractive sections;

- From the point of view of the area suitable for presenting the information, the upper and the right sides of the webpage seem to attract most of the attention; the use of images or sections clearly defined by colors, symbols or borders, can increase the attractiveness of the information presented in the other areas of the page;

- At the general level, the images, especially those with people, attract attention, being viewed in the case of each bank; the main pictures of the landing page and their titles are first viewed for each of the banks;

- We can see that when text-type information is presented alongside or as part of an image, it is more often and more quickly visualized; this way of presenting information increases the chances that the sections at the bottom of the page will be viewed.

Given the results presented above, hypothesis H1 is partly confirmed, several repeated visual behaviors being obtained, but not a certain pattern of visualization.

\section{Objective 2 - Determining the differences (ANOVA) of the perceived} difficulty for identifying the exchange rate between the banks' websites

Following the completion of each task, the subjects expressed the level of perceived difficulty in carrying out the task for each bank.

The unifactorial dependent ANOVA (Analysis of Variance) technique determines the way in which the dependent variable varies according to the categories of the considered factor. From the methodological point of view, the following hypotheses should be considered for the statistical accuracy of this analysis technique: (1) The dependent variable follows a normal distribution for each category of the considered factor; (2) The variance of the dependent variable within each category of the considered factor is a homogeneous one.

In the present case, the dependent variable $(\mathrm{Y})$ is the perceived (expressed) difficulty of completing task 1 (identifying the exchange rate), while the considered factors $(\mathrm{X})$ are the web pages of the five banks operating in Romania (Banca Transilvania, BRD, CEC Bank, OTP Bank and Piraeus Bank).The scales used to measure the two variables are interval for perceived difficulty (1-very

DOI: $10.24818 / 18423264 / 53.4 .19 .08$ 
Monica Țichindelean (Beca), Iuliana Cetină, Mihai Țichindelean, Violeta Rădulescu

difficult; 5 - very easy), respectively nominal with five categories for the Web pages.

In order to test the validity of the first ANOVA hypothesis regarding normal distribution, two statistic tests were applied: Kolmogorov-Smirnov and ShapiroWilk. The null hypothesis in both tests is that the distribution of the dependent variable (perceived difficulty) within each factor category (Web pages) is a normal distribution, implicitly the existence of a statistical significance of these two tests (Sig. <0.05) would imply a rejection of the null hypothesis and confirmation of a different distribution from a normal one of the dependent variable. The values of the two tests are presented in the following table.

Table 1. Kolmogorov-Smirnov and Shapiro-Wilk tests for the perceived difficulty of completing the task

\begin{tabular}{|c|c|c|c|c|c|c|c|}
\hline & \multirow{2}{*}{ Bank } & \multicolumn{3}{|c|}{ Kolmogorov-Smirnov ${ }^{\mathrm{a}}$} & \multicolumn{3}{|c|}{ Shapiro-Wilk } \\
\hline & & Statistic & Df & Sig. & Statistic & $\mathrm{df}$ & Sig. \\
\hline \multirow{5}{*}{ 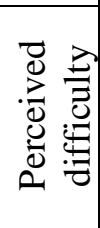 } & A & 0.191 & 22 & 0.037 & 0.906 & 22 & 0.039 \\
\hline & $\mathrm{B}$ & 0.296 & 22 & 0.000 & 0.838 & 22 & 0.002 \\
\hline & $\mathrm{C}$ & 0.263 & 22 & 0.000 & 0.883 & 22 & 0.014 \\
\hline & $\mathrm{D}$ & 0.256 & 22 & 0.001 & 0.883 & 22 & 0.014 \\
\hline & $\mathrm{E}$ & 0.315 & 22 & 0.000 & 0.742 & 22 & 0.000 \\
\hline
\end{tabular}

Due to the small number of categories (5) and the sample considered (22 respondents), there is a lower probability of obtaining a normal distribution of the dependent variable within the factor categories. From the above table it can be observed that the variable Perceived difficulty does not follow a normal distribution for any of the five banking web pages considered (Sig. <0.05), implicitly the first hypothesis for applying the ANOVA technique (a normal distribution of the dependent variable for each category) is not met.

Next, we test the second hypothesis specific to the ANOVA technique, namely the equal variance of the variable Perceived difficulty in fulfilling the task within the five banking web pages considered.

Table 2. Levene statistical test - the homogeneity of the variance of the perceived difficulty for competition of the task within each studied bank

\begin{tabular}{|c|c|c|c|c|}
\hline & $\begin{array}{l}\text { Levene } \\
\text { Statistic }\end{array}$ & df1 & df 2 & Sig. \\
\hline$\tau \Rightarrow$ Based on Mean & 0.883 & 4 & 105 & 0.477 \\
\hline$\therefore$ Based on Median & 0.741 & 4 & 105 & 0.566 \\
\hline Based on Median, with adjusted df & 0.741 & 4 & 95.046 & 0.566 \\
\hline Based on trimmed mean & 0.885 & 4 & 105 & 0.475 \\
\hline
\end{tabular}


The Levene test is not statistically validated $(0.477>0.05)$, therefore the null hypothesis is maintained, the variable Perceived difficulty in completing the task having the same variance within the five Banking Web Pages. Noting that only the second hypothesis required to apply the ANOVA technique is fulfilled, the results of the ANOVA technique application are presented below.

Table 3. ANOVA analysis for the perceived difficulty of completing the task according to each studied bank

\begin{tabular}{|l|c|c|c|c|c|}
\hline & Sum of Squares & df & Mean Square & F & Sig. \\
\hline $\begin{array}{l}\text { Between } \\
\text { Groups }\end{array}$ & 21.509 & 4 & 5.377 & & \\
\cline { 1 - 4 } $\begin{array}{l}\text { Within } \\
\text { Groups }\end{array}$ & 151.909 & 105 & 1.447 & \multirow{2}{*}{3.717} & 0.007 \\
\cline { 1 - 5 } Total & 173.418 & 109 & & \\
\hline
\end{tabular}

The $\mathrm{F}$ indicator, respectively the ratio between the systematic and nonsystematic variance of the dependent variable (perceived difficulty of fulfilling the task), has a value $F=3.717>1$, indicating that the dependent variable differs according to the categories of the considered factor. The contrast tests that will be performed will indicate whether the perceived difficulty differs depending on the Web pages of the five banks taken two by two.

Of the 10 contrasts developed (5 banks taken two by two), only contrast no. 4 (Banca Transilvania and Piraeus Bank), no. 9 (CEC Bank and Piraeus Bank) and no. 10 (OTP Bank and Piraeus Bank) are statistically significant. This indicates that the perceived difficulty for identifying the exchange rate offered by the banks is the lowest in the case of Piraeus Bank, followed by Banca Transilvania and then CEC Bank and OTP Bank with the same level of difficulty.

In this context, hypothesis $\mathbf{H 2}$ is confirmed, the perceived difficulty as a result of carrying out the task differs significantly depending on the website of the considered banks.

Objective 3- Determining the differences (ANOVA) of the measured difficulty (duration) in completing the task between the banks' websites

For each of the 22 subjects, the eye tracker recorded the time needed for the exchange rate to be identified on the five banks' websites. Therefore, the duration was the measured difficulty for completing the task. In this case, the dependent variable (Y) is the measured difficulty (duration) of completing the task, while the considered factors $(\mathrm{X})$ are the web pages of the five banks. The scales used to measure the two variables are ratio for measured difficulty, respectively nominal with five categories for the web pages.

To test the first hypothesis of the ANOVA technique regarding the normal distribution of the dependent variable (Duration) within each factor category (Web 
Monica Țichindelean (Beca), Iuliana Cetină, Mihai Țichindelean, Violeta Rădulescu

pages), two statistical tests were used: Kolmogorov-Smirnov and Shapiro-Wilk. The values of the two tests are shown in the table below.

Table 4. Kolmogorov-Smirnov and Shapiro-Wilk tests for the measured difficulty (duration) of completing the task

\begin{tabular}{|c|c|c|c|c|c|c|c|}
\hline & \multirow{2}{*}{ Bank } & \multicolumn{3}{|c|}{ Kolmogorov-Smirnova } & \multicolumn{3}{|c|}{ Shapiro-Wilk } \\
\hline & & Statistic & $\mathrm{df}$ & Sig. & Statistic & $\mathrm{df}$ & Sig. \\
\hline \multirow{5}{*}{ 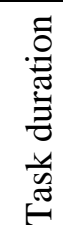 } & A & 0.239 & 20 & 0.004 & 0.832 & 20 & 0.003 \\
\hline & B & 0.177 & 17 & 0.162 & 0.915 & 17 & 0.121 \\
\hline & $\mathrm{C}$ & 0.172 & 20 & 0.123 & 0.961 & 20 & 0.565 \\
\hline & $\mathrm{D}$ & 0.181 & 20 & 0.084 & 0.917 & 20 & 0.085 \\
\hline & $\mathrm{E}$ & 0.146 & 22 & $0.200^{*}$ & 0.954 & 22 & 0.383 \\
\hline
\end{tabular}

Apart from category A - Banca Transilvania's web page (Sig.= 0.004 $<0.05$ ), the dependent variable Measured difficulty (Duration) follows a normal distribution within the factor categories.

The second hypothesis specific to the ANOVA technique - the homogeneity of the variance of the dependent variable within the factor groups is tested using the Levene statistical test. The test results are presented in the table below:

Table 5. Levene statistical test - homogeneity of duration variance within each studied bank

\begin{tabular}{|c|l|c|c|c|c|}
\hline \multicolumn{2}{|c|}{} & $\begin{array}{c}\text { Levene } \\
\text { Statistic }\end{array}$ & $\begin{array}{c}\text { df } \\
1\end{array}$ & df2 & Sig. \\
\hline \multirow{4}{*}{\begin{tabular}{c}
4 \\
\multirow{2}{*}{}
\end{tabular}} & Based on Mean & 9.466 & 4 & 94 & 0.000 \\
\cline { 2 - 6 } & Based on Median & 3.722 & 4 & 94 & 0.007 \\
\cline { 2 - 6 } & Based on Median, with adjusted df & 3.722 & 4 & 42.477 & 0.011 \\
\cline { 2 - 6 } & Based on trimmed mean & 8.313 & 4 & 94 & 0.000 \\
\hline
\end{tabular}

Regardless of how it is calculated, the Levene test is statistically significant (significance level <0.05), rejecting the null hypothesis and thus indicating the existence of a heterogeneity of the variance of the dependent variable within the factor groups. Comparing the values of the dependent variable variance according to the categories of the factor, it was found that the variance of the dependent variable (Duration) for category A (Web page of the Banca Transilvania) is much higher than in the other four categories. Given this fact, but also because the measured difficulty (duration) is not normally distributed in category A, we decided to eliminate this category from the analysis. Following the elimination, the two hypotheses necessary for applying the ANOVA technique were fulfilled: 
Table 6.Kolmogorov-Smirnov and Shapiro-Wilk tests for the measured difficulty (duration) of completing the task after eliminating Banca Transilvania

\begin{tabular}{|c|c|c|c|c|c|c|c|}
\hline \multirow{6}{*}{ 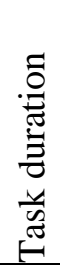 } & \multirow{2}{*}{ Bank } & \multicolumn{3}{|c|}{ Kolmogorov-Smirnov ${ }^{\mathrm{a}}$} & \multicolumn{3}{|c|}{ Shapiro-Wilk } \\
\hline & & Statistic & Df & Sig. & Statistic & $\mathrm{df}$ & Sig. \\
\hline & B & 0.177 & 17 & 0.162 & 0.915 & 17 & 0.121 \\
\hline & $\mathrm{C}$ & 0.172 & 20 & 0.123 & 0.961 & 20 & 0.565 \\
\hline & $\mathrm{D}$ & 0.181 & 20 & 0.084 & 0.917 & 20 & 0.085 \\
\hline & $\mathrm{E}$ & 0.146 & 22 & $0.200^{*}$ & 0.954 & 22 & 0.383 \\
\hline
\end{tabular}

and

Table 7. Levene statistical test - homogeneity of duration variance within each studied bank after eliminating Banca Transilvania

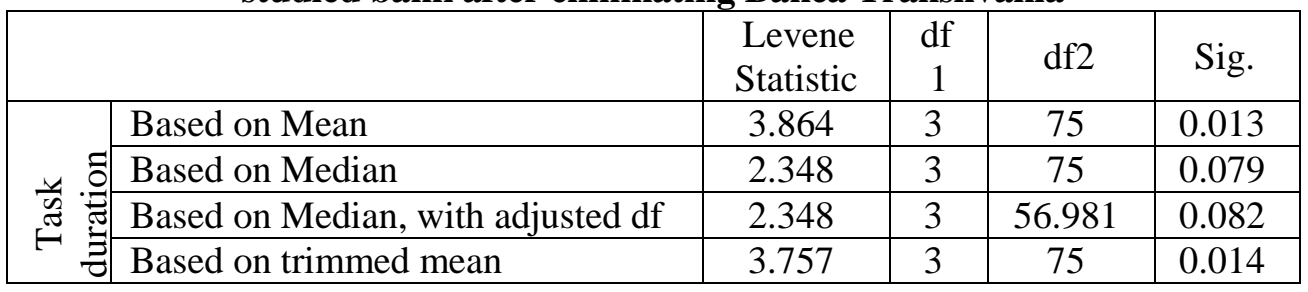

The results of the one-factor dependent ANOVA technique are presented below:

Table 8. ANOVA analysis for the measured difficulty (duration) of completing the task according to each studied bank

\begin{tabular}{|l|c|c|c|c|c|}
\hline & $\begin{array}{c}\text { Sum of } \\
\text { Squares }\end{array}$ & df & Mean Square & F & Sig. \\
\hline Between Groups & 0.027 & 3 & 0.009 & \multirow{2}{*}{7.168} & \multirow{2}{*}{0.000} \\
\hline Within Groups & 0.093 & 75 & 0.001 & & \\
\hline Total & 0.119 & 78 & & \\
\hline
\end{tabular}

For the duration of the first task, the value of indicator $\mathrm{F}=7.168$ and the level of statistical significance of this value is 0.00 , not exceeding the limit value of 0.05 . It can therefore be concluded that the dependent variable differs according to the categories of the factor considered, meaning that the structure of the main pages of the websites of the four banks influences the duration of the first task ( $\mathrm{F}=$ 7.168> 1). The contrast tests that were performed indicate whether the duration of the first task differs depending on the Web pages of the four banks taken two by two. Of the 8 contrasts developed, only 4 of them present statistically

DOI: $10.24818 / 18423264 / 53.4 .19 .08$ 
Monica Țichindelean (Beca), Iuliana Cetină, Mihai Țichindelean, Violeta Rădulescu

representative differences of the measured difficulty for completing the task. Therefore, we can say that the duration of the task is significantly lower for BRD compared to CEC Bank or OTP Bank, the duration for CEC Bank is statistically lower that for OTP Bank, and the duration of the task is lower for Piraeus Bank compared to OTP Bank.

In order to have an overview on the difficulty of completing the task, namely identifying the exchange rate presented on each of the five banking websites, but also in order to identify the form and position of the information that increases the usability of the webpage, we will analyze in the following the indicators previously obtained. Thus, we will track the duration of the task for each bank, considering the cases in which this variable presents statistically representative differences.

Table 9. Indicators of the task for each studied bank

\begin{tabular}{|c|c|c|c|c|c|}
\hline & $\begin{array}{c}\text { Banca } \\
\text { Transilvania } \\
\end{array}$ & BRD & $\begin{array}{l}\text { CEC } \\
\text { Bank }\end{array}$ & OTP Bank & $\begin{array}{c}\text { Piraeus } \\
\text { Bank }\end{array}$ \\
\hline $\begin{array}{l}\text { Measured } \\
\text { difficulty } \\
\text { (duration) }\end{array}$ & 0.205 & 0.139 & 0.124 & 0.137 & 0.077 \\
\hline $\begin{array}{l}\text { Statistically } \\
\text { representative } \\
\text { difference of } \\
\text { duration } \\
\text { compared to: }\end{array}$ & - & $\begin{array}{c}\text { CEC } \\
\text { Bank; } \\
\text { OTP } \\
\text { Bank }\end{array}$ & $\begin{array}{l}\text { BRD; } \\
\text { OTP } \\
\text { Bank }\end{array}$ & $\begin{array}{c}\text { CEC Bank; } \\
\text { Piraeus } \\
\text { Bank }\end{array}$ & $\begin{array}{l}\text { OTP } \\
\text { Bank }\end{array}$ \\
\hline $\begin{array}{l}\text { Information } \\
\text { type }\end{array}$ & $\begin{array}{l}\text { Small } \\
\text { symbol }\end{array}$ & $\begin{array}{c}\text { Small } \\
\text { symbol }\end{array}$ & $\begin{array}{l}\text { Large } \\
\text { symbol }\end{array}$ & $\begin{array}{l}\text { Graph and } \\
\text { value }\end{array}$ & $\begin{array}{l}\text { Table } \\
\text { with } \\
\text { values }\end{array}$ \\
\hline $\begin{array}{l}\text { Information } \\
\text { position }\end{array}$ & Central & $\begin{array}{l}\text { Top- } \\
\text { main } \\
\text { menu }\end{array}$ & $\begin{array}{l}\text { Central- } \\
\text { right }\end{array}$ & Bottom-right & $\begin{array}{c}\text { Bottom- } \\
\text { left }\end{array}$ \\
\hline
\end{tabular}

By analyzing the indicators presented above we can see that the task was completed in the shortest time in the case of Piraeus Bank. According to ANOVA, the average duration in the case of Piraeus Bank differs statistically from the duration of the task for OTP Bank. Thus, we can conclude that the presentation of the exchange rate in tabular form, as is the case with Piraeus Bank, is the most easily identifiable for users, compared to the graphical form used in the case of OTP Bank.

The second shortest duration is found in the case of BRD, which is statistically significantly different from the duration of the task in the case of OTP Bank and CEC Bank. From the point of view of the information presentation form, we can conclude that the presentation of the exchange rate in the form of a symbol 
at the top of the web page is preferable to the graphical option positioned in the bottom-right (OTP Bank) or to the symbolic variant positioned in the center of the page (CEC Bank). Comparing CEC Bank and OTP Bank, we can say that the graphical presentation of the exchange rate is preferable to the symbol placed in the central area informing about the exchange rate.

Based on the ideas presented above, we can conclude that, when we refer to the presentation of the exchange rate on the web page of a bank, the following forms and positions of the information are considered effective in order for the identification of this information to be easy: (1) table form, (2) symbol in the main top menu bar, (3) graphic form, (4) large size symbol in the center of the page and (5) small size symbol in the central part of the page.

Based on the information prior obtained, hypothesis $\mathbf{H 3}$ is confirmed, as the measured difficulty (duration) of fulfilling the task differs significantly depending on the website of the considered banks.

Objective 4 - Identifying the relationship between the perceived and measured difficulty for completing the task

Both variables studied before present the difficulty of completing the task, namely identifying the exchange rate offered by each of the five considered banks on their webpages. The correlation coefficients (Pearson and Spearman) between the perceived and measured difficulty for each bank indicate the level of comprehension of the subject over the difficulty of the task. The following table presents the correlation coefficients obtained for the two variables:

Table 10. Correlations between perceived and measured difficulty of completing the task

\begin{tabular}{|l|c|c|c|c|c|}
\hline & $\begin{array}{c}\text { Banca } \\
\text { Transilvania }\end{array}$ & BRD & $\begin{array}{c}\text { CEC } \\
\text { Bank }\end{array}$ & $\begin{array}{c}\text { OTP } \\
\text { Bank }\end{array}$ & $\begin{array}{c}\text { Piraeus } \\
\text { Bank }\end{array}$ \\
\hline Pearson correlation & $-0.498^{*}$ & -0.454 & -0.409 & $-0.501^{*}$ & $-0.501^{*}$ \\
\hline Spearman correlation & $-0.552^{*}$ & $-0.474^{*}$ & -0.188 & $-0.586^{* *}$ & $-0.586^{* *}$ \\
\hline$*$. Correlation is significant at the 0.05 level (2-tailed). \\
\hline **. Correlation is significant at the 0.01 level (2-tailed). \\
\hline
\end{tabular}

Given that all the calculated correlation coefficients indicate a medium or strong negative relation between the perceived and measured difficulty, we can conclude that when the measured difficulty (duration) decreases, the perceived difficulty will decrease as well. In other words, the perceived level of difficulty is in accordance with its measured level, in general subjects correctly assessing the ease of performing the task.

DOI: $10.24818 / 18423264 / 53.4 .19 .08$ 
Monica Țichindelean (Beca), Iuliana Cetină, Mihai Țichindelean, Violeta Rădulescu

In the context where all the correlation coefficients indicate a negative relation between the perceived and measured difficulty of identifying the exchange rate on the website of the five considered banks, hypothesis $\mathbf{H} 4$ is confirmed.

\section{Conclusions and discussions}

As past studies indicate the value of the eye tracking technique in studying consumer behavior in general and website usability in particular, the present paper offers a series of valuable results for understanding the way consumers interact with banking webpages and also suggestions for improving users' online banking experience. Based on the analysis of consumers' eye movement while performing a task on the webpage of five different banks, results show that the main route of consumers' gaze follows a vertical direction, starting from the upper side of the webpage and going down, until shifting to information that stands out due to its color or format. Besides the upper area of the webpage that is always viewed first, the attention attracted by the right side of the screen appears to be significant as well. As images, especially those presenting persons, attract most of the attention compared to other ways of presenting the information, the use of images and text overlaid on images are considered to be the proper approach in increasing the attention rate on the left and lower areas of a banking webpage; also, the use of colors, clearly differentiated sections or symbols can contribute to this objective.

When it comes to the difficulty of performing a task on the website of a bank, within this study two different measurements of difficulty were used: perceived difficulty of completing the task was obtained through a questionnaire where subjects expressed how they perceived the task difficulty, while measured difficulty was calculated based on the duration needed for the task to be successfully completed. The analysis of variance (ANOVA) of both difficulty measurements showed that the perceived and the measured difficulty of completing the task significantly differ depending on the website of the five considered banks. This result indicates that characteristics like the format, colors, fonts, structure and position of the information presented on a banking website influence the ease of performing a task, therefore the users' experience quality as well.

Last, but not least, when it comes to the cognition of task completion difficulty, the correlation coefficients calculated between the perceived and measured difficulty of performing a task on the website of the five considered banks indicate a medium or strong negative relation between the two dimensions. By proving that when the measured difficulty (duration) decreases, the perceived difficulty will decrease as well, we could conclude that the subjects of the study correctly assessed the ease of performing the task, the results showed by the analysis of both difficulty dimensions being therefore valid.

DOI: 10.24818/18423264/53.4.19.08 


\section{REFERENCES}

[1] Bergstrom, J.C.R, Olmsted-Hawala, E.L., Jans, M.E. (2013), Age-Related Differences in Eye Tracking and Usability Performance: Website Usability for Older Adults. International Journal of Human-Computer Interaction, 29/8: 541548 ;

[2] Bojko, A. (2013), Eye Tracking the User Experience: A Practical Guide to Research, Rosenfeld Media; 1st edition;

[3] Cătoiu, I. (coord) (2009), Tratat de cercetări de marketing, Uranus Publishing; Bucharest;

[4] Chi, E.H., Gumbrecht, M., Hong, L. (2007), Visual Foraging of Highlighted Text: An Eye-Tracking Study. Human-Computer Interaction, Part III, 589-598; [5] Cyra, D., Headb, M., Larios, H. (2010), Colour Appeal in Website Design within and across Cultures: A Multi-Method Evaluation. International Journal of Human-Computer Studies;

[6] Djamasbi, S., Siegel, M., Tullis, T. (2010), Generation Y, Web Design, and Eye Tracking. International Journal of Human Computer Studies,68/5: 307-323; [7] Durgin, F. H., Doyle, E., Egan, L. (2008), Upper-left Gaze bias Reveals Competing Search Strategies in a Reverse Stroop Task. Acta Psychologica, 127(2);

[8] Fidelis, B.T, Oliveira, J.H.C, Giraldi, J.E., Santos, R.O.J, (2017), Sexual Appeal in Print Media Advertising: Effects on Brand Recall and Fixation Time. Research Journal of Textile and Apparel, 21/1:42 - 58;

[9] Hoeks, B., Levelt, W.J.M. (1993), Pupillary Dilation as a Measure of Attention: A Quantitative System Analysis. Behavior Research Methods, Instruments, \& Computers, 25 (1): 16-26;

[10] Menon, V.R.G., Sigurdsson, V., Larsen, N.M., Fagerstrom, A., Foxall, G.R. (2016), Consumer Attention to Price in Social Commerce: Eye Tracking Patterns in Retail Clothing. Journal of Business Research, 69 (11): 5008-5013; [11] Milosavljevic, M., Koch, C., Rangel, A. (2011), Consumers Can Make Choices in as Little as a Third of a Second. Judgment and Decision Making, 6(6), 520-530;

[12] Mohr, G.S., Lichtenstein, D.R, Janiszewski, C. (2012), The Effect of Marketer-Suggested Serving Size on Consumer Responses: The Unintended Consequences of Consumer Attention to Calorie Information. Journal of Marketing, 76: 59-75;

[13] Munoz-Leiva, F., Hernandez-Mendez, J., Gomez-Carmona, D. (2019), Measuring Advertising Effectiveness in Travel 2.0 Websites through Eyetracking Technology. Physiology \& Behavior, Vol.200, 83 - 95;

DOI: 10.24818/18423264/53.4.19.08 
Monica Țichindelean (Beca), Iuliana Cetină, Mihai Țichindelean, Violeta Rădulescu

[14] Pieters, R., Wedel, M. (2007), Goal Control of Visual Attention to Advertising: The Yarbus Implication. Journal of Consumer Research, 34, 224 233;

[15] Pieters, R., Rosbergen, E., Wedel, M. (1999), Visual Attention to Repeated Print Advertising: A Test of Scanpath Theory. Journal of Marketing Research, 36/4: 424-438;

[16] Płużyczka, M. (2018), The First Hundred Years: A History of Eye Tracking as a Research Method. Applied Linguistics Papers, 25/4: 101-116;

[17] Pop, N.A., Dabija, D-C., Iorga A.M. (2014), Ethical Responsibility of Neuromarketing Companies in Harnessing the Market Research - A Global Exploratory Approach. Amfiteatrul Economic, 16 (35): 26-40;

[18] Smeureanu, I., Reveiu, A., Kanala, R., Moresino, F. (2014), Understanding Behavior, Perception and Attitudes of Domestic Lightning Consumers in Romania. Proceedings of the IE 2014 International Conference : 345-351;

[19] Smidts, A. (2002), Looking into the Brain: On the Prospects of Neuromarketing. ERIM Inaugural Address Series Research in Management; [20] Wang, Q., Yang, S., Liu, M., Cao, Z., Ma, Q. (2014), An Eye-tracking Study of Website Complexity from Cognitive Load Perspective. Decision Support Systems;

[21] Zlokazova, T., Blinnikova, I., Grigorovich, S., Burmistrov, I. (2019), Search Results on Flight Booking Websites: Displaying Departure and Return Flights on a Single Page vs Two Consecutive Pages. International Federation for Information Processing 2019, Published by Springer Nature Switzerland AG 2019, $668-671$. 